Running head: PERCEPTIONS OF INTOXICATED WITNESSES

Memory and Credibility Perceptions of Alcohol and Other Drug Intoxicated Witnesses and Victims of Crime

Lauren A. Monds ${ }^{1 \mathrm{a}}$, Hayley J. Cullen ${ }^{2}$, Lilian Kloft ${ }^{3}$, Celine van Golde ${ }^{2}$, Anthony W. Harrison ${ }^{1}$ and Heather D. Flowe ${ }^{4}$

1. Specialty of Addiction Medicine, Faculty of Medicine and Health, The University of Sydney, Australia

2. School of Psychology, Faculty of Science, The University of Sydney, Australia

3. Faculty of Psychology and Neuroscience, Maastricht University, The Netherlands

4. School of Psychology, University of Birmingham

${ }^{\mathrm{a} C}$ Correspondence should be directed to Lauren A. Monds, $\underline{\text { lauren.monds@ } @ \text { sydney.edu.au }}$

Date: $18^{\text {th }}$ December 2020

Abstract word length: 198

Word length: 5,935 


\begin{abstract}
Research into juror perceptions regarding the impact of intoxication on eyewitness memory and credibility is scarce for substances other than alcohol. However, jurors are frequently told to draw on their personal beliefs and experience with intoxicating substances to infer their impact on the case. It is therefore important to investigate laypeople's perceptions regarding witness and victim intoxication across a range of substances, and whether these perceptions are associated with substance familiarity. Participants $(n=470)$ completed a survey assessing familiarity and use of different substances, as well as perceptions regarding effects on the memory and credibility of intoxicated victims and witnesses. While participants most frequently reported believing that alcohol, hallucinogens, and polysubstance use of alcohol and cannabis have large negative effects on memory, they more frequently reported that they do not know the extent to which cannabis and cocaine affect memory. In addition, attitudes were found to vary based on substance familiarity. Differences with respect to the perceived impact on memory and credibility of various substances have relevance to court proceedings, particularly in terms of voir dire procedures and whether an expert witness may be required to educate the court on the impacts of different forms of intoxication.
\end{abstract}

Keywords: eyewitness testimony, memory, credibility, alcohol, drugs 


\section{Memory and Credibility Perceptions of Alcohol and Other Drug Intoxicated Witnesses and Victims of Crime}

Accurate witness and victim testimony can be essential to solving a crime. However, inaccurate testimony can mislead an investigation or result in failures of the justice system. People who have used alcohol and other drugs (AOD) are frequently witness to crime (Palmer et al., 2013). AOD intoxication by witnesses and victims is problematic for police and courts, given the concerns that it raises about whether they are able to provide an accurate and complete account of the events they are asked to recall. In addition, perceptions regarding the credibility of intoxicated witnesses have important implications for the approach taken to criminal investigations and court proceedings (Evans \& Schreiber Compo, 2010). Reduced credibility of witnesses can impact decisions regarding whether and how to prosecute, especially when other evidence of the defendant's guilt is weak or lacking (see Flowe et al., 2011). Erroneous witness testimony is also a leading cause of wrongful convictions (e.g., Innocence Project, 2020; Kassin \& Gudjonsson, 2004), highlighting the importance of juror perspectives regarding the effects of intoxication on the memory and credibility of witness testimony.

There has been increasing interest in recent years regarding the effect of alcohol intoxication on memory (e.g., Altman et al., 2019; Jores et al., 2019; Monds et al., 2017). A growing body of evidence suggests that alcohol intoxication decreases the completeness but not the accuracy of event recall (Altman et al., 2018; Crossland et al., 2018; Flowe et al., 2016; Jores et al., 2019; van Oorsouw \& Merckelbach, 2012). Similarly, face recognition does not appear to be impaired with low to moderate Blood Alcohol Concentration (BACs; e.g., Colloff \& Flowe, 2016; Flowe et al., 2017; Monds et al., 2019). Other research findings suggest that the relationship between alcohol intoxication and susceptibility to false memories (i.e., recall or recognition of an 
event, or details about an event, that did not occur) is influenced by the level of intoxication and time of recall. In particular, findings suggest that low to moderate levels of alcohol intoxication are not significantly related to false memory susceptibility when recalled immediately after an event (Schreiber Compo et al., 2012) or after a one week delay (Flowe et al., 2019). However, increased suggestibility (i.e., agreement with false information given on an intervening forcedchoice test) has been observed following a one-week delay when recalling the event (Evans et al., 2019) and for severely intoxicated individuals when the misinformation is presented using forced choice and closed questions (van Oorsouw et al., 2019; van Oorsouw et al., 2015).

Evidence regarding the role of other substance effects on eyewitness memory is still in its infancy (for a review see Kloft, Monds, et al., 2020). However, the increasing prevalence of illicit substance use and prescription drug misuse (e.g., AIHW, 2016; Winstock, 2019) necessitates further investigation into the effects of these substances on memory. Several previous studies examining the impact of cannabis intoxication on eyewitness memory suggest that, despite reduced completeness of recall, the accuracy of information recalled about events witnessed while intoxicated remains unaffected (Vredeveldt et al., 2018; Yuille et al., 1998). However, more recent research with participants who had self-intoxicated with cannabis, and then learned and were immediately tested on faces using an old/new recognition test, showed lower discrimination accuracy and lower confidence-specific accuracy at high levels of confidence compared to participants who were not intoxicated (Pezdek et al., 2020). Moreover, in another recent study, which used virtual reality-based crime scenarios, participants that were intoxicated with cannabis were found to be significantly more likely to form false memories than those receiving a placebo (Kloft, Otgaar, Blokland, Monds, et al., 2020). Together these studies suggest that the reliability of a witness's memory for events that were observed while intoxicated with cannabis may be 
compromised. In contrast, a similar placebo-controlled study that examined the effects of intoxication with 3,4-Methylenedioxymethamphetamine (MDMA; the main psychoactive ingredient of ecstasy) did not show increased suggestibility to misinformation (Kloft, Otgaar, Blokland, Toennes, et al., 2020).

These findings on the heterogenous effects of different types of substances on memory highlight that is it important for courts to consider that the effects of a given substance on a witness' memory accuracy and reliability depend on the specific substance consumed. Moreover, triers of fact will be better able to remedy inaccurate juror perceptions if they have a better understanding of the assumptions that jurors are likely to make about the effects of different substances on memory.

At present, there appear to be no studies published on the effect of other substances in an eye-witness context. In addition, research has not yet considered the effects of polysubstance use (i.e., using two or more substances at the same time) on eyewitness memory. Substance use is related to crime in a myriad of ways, ranging from drug manufacture and possession, to their effects on behaviour (e.g., Dietze et al., 2013; Kloft, Monds, et al., 2020); therefore, it is of wide interest to understand how prospective jurors perceive the memory accuracy and credibility of witnesses who were acutely intoxicated with different types of substances, including multiple types of substances, at the time of the crime.

Surveys of lay persons, including jury-eligible members of the public, suggest that people commonly believe alcohol impairs witness memory (Benton et al., 2006; Houston et al., 2013; Lynch et al., 2013). A mock-juror study (Evans \& Schreiber Compo, 2010) revealed that participants were sensitive to the potential for alcohol to have a negative effect on witnesses' memory ability, but did not appear to consider dose-dependent effects. Furthermore, participants' 
perceptions of witness impairment informed their witness' credibility ratings and consequently their verdicts. Another mock juror study found that defendants were less likely to be found guilty if rape victims had consumed alcohol prior to the event (Schuller \& Wall, 1998). In light of studies demonstrating that alcohol intoxication affects the completeness but not accuracy of memory, these findings may reflect misconceptions among the general public regarding how alcohol intoxication affects memory. In addition, although mock jury studies have investigated credibility perceptions with regard to alcohol intoxication, they have not explored attitudes toward intoxication with other substances (e.g., cannabis, amphetamines, opioids etc.) or polysubstance use.

Jurors' own personal experience may be a crucial factor to understanding perceptions of the memory and credibility effects associated with intoxication. In court, jurors are frequently responsible for determining eyewitness credibility (Slovenko, 2004) and are often asked to assess the relevance of alcohol to the facts of the case by drawing on their own personal experience rather than scientific evidence (Quilter \& McNamara, 2018). If in the past jurors have consumed the substance of interest and do or do not remember having experienced memory issues as a result, this may influence their assessment of the substance's effects on the witnesses in the case. Thus, prospective juror's personal history with regard to different substance classes have clear relevance to voir dire proceedings (i.e., the selection of a fair and impartial jury).

Previous research exploring the relationship between personal experience and perceptions of how drugs affect memory performance have yielded mixed results. In a survey regarding the perception of confessions given by alcohol-intoxicated suspects, Mindthoff et al. (2019) found that participants' own drinking habits did not impact upon responses. However, Evans and Schreiber Compo (2010) found a negative relationship between personal alcohol consumption and perceived 
accuracy of sober witnesses, with individuals who reported consuming more alcohol rating sober witnesses as being more impaired. At the same time, participant ratings of an intoxicated witness's memory accuracy did not vary in relation to their own personal alcohol consumption. Given the mixed findings with regard to how personal experience affects judgments of alcohol-intoxicated and sober witnesses, it is important that these findings are clarified through further investigation. Moreover, the potential effects of personal experience with substances other than alcohol on perceptions of associated memory impairment should be examined.

\section{The current study}

We administered a survey to investigate perceptions regarding the memory effects of AOD intoxication, as well as the perceived credibility of witnesses and victims providing testimony regarding a crime that occurred while they were intoxicated. We assessed perceptions of intoxication with a range of substances (e.g., alcohol, cannabis, stimulants, sedatives, and hallucinogens) and substance combinations (i.e., polysubstance use, e.g., alcohol and cannabis taken together). Because past research has predominantly focused on alcohol, it is important that gaps are addressed with respect to other substances and their combinations. Another major aim of the study was to investigate the extent to which participant familiarity with each substance, whether through their own personal use or through observing others who had consumed the drug, influences perceptions of the drug's effects on memory. This information may help inform legal practitioners about whether prospective jurors' personal experiences are likely to impact their perceptions of eyewitness and victim memory accuracy and credibility. Legal professionals will also benefit from an improved understanding regarding the types of information jurors should be educated about to avoid misconceptions about the effects of drugs on memory during criminal proceedings. 


\section{Method}

\section{Participants}

Participants included 498 first-year psychology students in Australia, who participated in exchange for course credit. Of these, 19 participants were excluded for failing to provide substantive data, and nine responses were excluded because they completed the survey twice (only their first response was retained). The final sample therefore included 470 participants $(77.7 \%$ female). All participants were above the legal drinking age in Australia (18 years) and were presumed jury-eligible, with participants ranging from 18 to $53(M=20.54, S D=5.05)$ years. The majority of participants (91.7\%) were Australian residents.

\section{Materials and Procedure}

The study was approved by the University of Sydney Human Research Ethics Committee and all participants gave informed consent before their participation. The questionnaire was adapted from a survey of law enforcement officers that explored perceptions about alcohol intoxication (Evans et al., 2009). Notably, the original survey only asked questions regarding alcohol intoxication; therefore, the current survey was extended to include a range of additional substances, including amphetamines, cannabis, cocaine, ecstasy, gamma-hydroxybutyrate (GHB), hallucinogens, opioids, sedatives, along with combinations involving two substances (e.g., alcohol and cannabis, alcohol and amphetamines). Police-specific questions from the original survey were removed (e.g., questions about interviewing procedures) and additional questions were added regarding observable cues to intoxication. The survey consisted of a combination of Likert-type scale, multiple choice, and open-ended questions, similar to Evans et al. (2009). While participants were required to answer questions based on their familiarity with the given substance, they were 
able to respond with "I don't know" if they were unsure of an answer, or "prefer not to answer" due to the sensitivity of the research topic (see Appendix - Survey Questions for additional information).

\section{Demographics}

Participants were asked about their age, gender, country of residence, employment status, whether they had worked in a role where they served alcohol, and whether they previously obtained any alcohol accreditation (i.e., training in the responsible service of alcohol). It is worth noting that there is a legal requirement in Australia to obtain alcohol accreditation to work in a role providing alcohol.

\section{Substance Use History and Familiarity}

Participants were asked to indicate whether they were familiar with the effects of each substance and substance combination. Familiarity in this instance was defined as prior personal or witnessed consumption, or general knowledge. Participants only received follow-up questions about these substances or any combination of substances with which they reported familiarity, with the exception that all participants answered questions relating to alcohol and cannabis. Since alcohol and cannabis are, along with tobacco, the most widely used recreational substances worldwide (e.g., Winstock, 2019) and also frequently implicated in crime across several countries (Evans et al., 2009; Kloft, Monds, et al., 2020; Palmer et al., 2013), it was assumed that participants would have sufficient familiarity with these substances to provide a response. Thus, these were compulsory questions to all.

For each substance and combination of substances, participants were asked about their personal experience, including history and frequency of their own consumption based on the Alcohol Use Disorders Identification Test (AUDIT-C; Bush et al., 1998). They were also asked 
how frequently they had witnessed others consuming that substance. In addition, participants were asked about the ease or difficulty in their detecting intoxication for each substance and substance combination, the visual and verbal signs they use to determine intoxication, and their perceived accuracy of each sign in detecting intoxication. However, intoxication detection is not a focus of the present investigation and therefore, will not be discussed further in this article.

\section{Intoxication and crime}

For each substance and combination of substances with which participants reported being familiar, they were asked whether they had ever witnessed a crime in which either the victim or suspect was perceived to be intoxicated at the time.

\section{Intoxication, memory and credibility}

For each substance or combination of substances that participants indicated familiarity with, they were asked about their perceptions regarding the effect of that substance/combination on eyewitness and victim memory accuracy and credibility. Specifically, participants were asked five questions regarding their perceptions of how intoxication by each substance and substance combination affects event memory. First, participants were asked to rate the degree to which intoxication negatively affects a person's memory of events, using a five-point Likert scale ranging from "not-at-all" to "extremely". Second, participants were asked to rate the credibility of an intoxicated witness compared to a non-intoxicated (i.e., sober) witness (i.e., "just as credible", "less credible" or "more credible"). They were also asked this question with respect to victims of crime. Lastly, participants were asked to indicate when witnesses and victims intoxicated by each substance or combination of substances at the time the crime occurred would be the most accurate. Perceptions regarding memory effects over time are not the focus of the current investigation and therefore not discussed further in this article. 


\section{Research Questions and Data Analysis}

The current investigation sought to address the following questions:

1) How familiar are participants with the different substances (own or witnessed consumption)?

2) Have participants ever experienced a crime involving AOD use?

3) How do participants perceive AOD intoxicated victims and witnesses of crime in terms of their memory and credibility?

4) Is past personal or witnessed AOD use (or in the case of alcohol, past work serving alcohol to others) related to participants' perceptions of memory accuracy and credibility?

Descriptive statistics (means, standard deviations and/or frequencies) were generated for the data reflecting demographics, substance familiarity, experience with AOD-related crime, and perceptions regarding the memory and credibility of intoxicated witnesses. Pearson's Chi Square Goodness of Fit analyses were conducted to assess participant responses across the different substances. Following this, Pearson's Chi Square Tests of Independence (or Fisher's Exact Tests where this was indicated by small cell counts) were conducted to assess participant perceptions for the different substances by personal/witnessed consumption and experience serving alcohol. Cramer's V was used to evaluate effect sizes.

\section{Results}

\section{Experience, Familiarity, and Consumption of Substances}

In total, $26.2 \%$ of participants reported having completed some form of alcohol accreditation (i.e., Responsible Service of Alcohol or equivalent) and 21.9\% reported previous experience in an occupation that involved the service, sale or supply of alcohol. Table 1 provides the proportion of participants that were familiar with each substance and polysubstance 
combination. As expected, the majority of participants were familiar with alcohol (93.6\%), with the second most-familiar substance being cannabis (51.1\%). Familiarity with the remaining drugs was relatively low $(\leq 30.9 \%$ of the sample was familiar with each of the other substances).

Participants were asked to indicate how frequently they consume alcohol, cannabis and each of the other substances with which they reported familiarity. They were also asked to indicate how often they witness the consumption of each of these substances. Due to low cell counts across a number of substances, results relating to the frequency of personal and witnessed consumption were collapsed from a five-point Likert scale (i.e., "never", "less than monthly", "monthly", "weekly", "daily or almost daily") to a two-point dichotomous scale (i.e., "never consumed/witnessed" or "consumed/witnessed"). As shown in Table 1, participants' self-reported own personal and/or witnessed consumption of different types of drugs was highest for alcohol (86.1\% and $97.9 \%$, respectively). For all substances and substance combinations, a larger proportion of participants reported having witnessed another person's consumption than having consumed the substance themselves. Because only a small proportion of participants reported familiarity with heroin and GHB $(8.9 \%$ and $4.9 \%$, respectively), these substances were excluded from further analysis.

\section{[table 1 here]}

Table 1 also provides the number and proportion of respondents that reported being familiar with each combination of polysubstance intoxication. In total, $33.7 \%$ of the sample reported that they had personally consumed or witnessed the consumption of two substances at the same time. Aside from Alcohol and Cannabis, with which $30.9 \%$ of participants said they were familiar, low familiarity was reported for each substance combination. The combination of Alcohol and Ecstasy was the next most familiar combination, with $10.4 \%$ of participants reporting 
familiarity. Due to low levels of familiarity, each substance combination, except Alcohol and Cannabis, was excluded from further analyses.

\section{Intoxication and Crime}

For participants that reported having witnessed a crime involving AOD, alcohol was the substance most frequently implicated (19.4\% of all participants), followed by amphetamines $(12.3 \%)$, ecstasy $(3.9 \%)$, cocaine $(2.6 \%)$, sedatives $(2.2 \%)$, and alcohol and cannabis combined (2.1\%). Cannabis was reported least often as being involved in witnessed crime (1.7\%). Participants that reported having witnessed a crime involving AOD were asked to provide details regarding the nature of the crime. Physical assault was the most commonly reported crime for all substances except cannabis, for which theft was most commonly reported. No participants reported having witnessed a crime related to hallucinogen intoxication.

\section{Intoxication, Memory and Credibility}

To understand participants' beliefs regarding how each substance affects memory, participants were asked the following questions: 1) To what extent do you believe the substance negatively affects memory of events? 2) Do you believe a witness/victim intoxicated by the substance would be less credible, just as credible, or more credible, than a sober witness/victim?

\section{Negative impact of intoxication on memory}

Due to low cell counts among some of the response options, these were collapsed into four main categories (i.e., "little negative effect", "moderate negative effect", "large negative effect", and "don't know"). A high proportion of participants reported that intoxication with alcohol, hallucinogens, or alcohol and cannabis combined, is associated with "large negative effects" on

memory (see Table 2). In contrast, participants frequently reported that they "don't know" how much cannabis and cocaine intoxication negatively affects memory. Chi-square analyses for all 
other substances (i.e., amphetamines, ecstasy, and sedatives) were not significant (all $p \mathrm{~s}>.145$ ), suggesting that beliefs regarding intoxication and memory based on these substances were relatively equally distributed across response options (see Table 2).

\section{[table 2 here]}

Perceptions regarding the effect of cannabis consumption on memory varied between those that reported having consumed cannabis and those who reported never having done so, $\chi^{2}(3, N=$ $453)=50.85, p=<.001$, Cramer's $V=.335$. A higher proportion of those who reported having consumed cannabis perceived it as having "little negative effect" on memory compared to those who had never consumed cannabis (54\% vs $18 \%$ ), while those who reported never having consumed cannabis more frequently reported that they "don't know" compared to those who had (38\% vs 9.6\%). Similar differences emerged between participants who reported ever having witnessed cannabis being consumed and those who reported never having done so, $\chi^{2}(3, N=453)$ $=29.84, p<.001$, Cramer's $V=.257$. Significant differences were also observed regarding the memory effects associated with ecstasy intoxication between participants who reported having previously consumed ecstasy and those who reported never having done so, $\chi^{2}(3, N=124)=12.90$, $p=.005$, Cramer's $V=.322$. A higher proportion of those who had consumed ecstasy reported that it had "little negative effect" on memory compared to those who had not consumed ecstasy (45.9\% vs $17.0 \%)$, while those who had not previously consumed ecstasy more frequently reported that they "don't know" (36.4\% vs 16.2\%). Perceptions of memory accuracy for the other substances did not significantly differ as a function of personal or witnessed consumption (all $p$ s $>.06$ and all $p s>.17$, respectively).

Given that the vast majority of the sample reported having personally consumed or witnessed the consumption of alcohol, beliefs about memory for alcohol were instead examined 
on the basis of whether or not participants reported holding accreditation to serve alcohol. Perceptions with regard to the memory effects of alcohol intoxication were not found to differ significantly between these groups, $F E T=2.14, p=.56$, Cramer's $V=.07$.

\section{Perceived credibility of intoxicated witnesses}

Participant responses to questions regarding the effect of intoxication on witness and victim credibility were highly similar (see Table 3 and Table 4). Because responses that an intoxicated witness would be "more credible" than a sober witness were rare, analyses were constrained to include only "less credible", “just as credible”, and “don’t know” response options.

For all substances, chi-square analyses indicated an association between witness intoxication and perceived credibility. The proportions of participants reporting that intoxicated witnesses are "less credible" were higher than those suggesting that they are "just as credible". While this pattern generally held for victim credibility as well, the one-way chi-square for sedatives was not found to be statistically significant.

\section{[tables 3 and 4 here]}

The perceived credibility of cannabis-intoxicated witnesses differed significantly between participants who reported having previously consumed cannabis and those reporting that they had not, $\chi^{2}[2, N=442]=31.972, p<.001$, Cramer's $V=.269$. Participants who reported having consumed cannabis provided fewer “don't know" responses compared to non-consumers (9.8\% vs $28.8 \%$ ). In addition, a higher proportion of consumers than non-consumers reported believing that the cannabis-intoxicated witness would be just as credible as a non-intoxicated person $(31.7 \%$ vs 9.9\%). Similar differences in perceived credibility were observed between participants who reported having previously witnessed others consuming cannabis and those reporting that they had not, $\chi^{2}(2, N=442)=13.65, p=.001$, Cramer's $\mathrm{V}=.176$. 
Differences in perceived credibility of ecstasy-intoxicated witnesses were also observed between participants that reported previously having consumed ecstasy and those reporting that they had not, $F E T=14.60, p<.001$, Cramer's V $=.365$. Compared with participants who reported never having consumed ecstasy, a higher proportion of those reporting previous consumption thought that witnesses who were intoxicated by ecstasy would be just as credible as sober witnesses (5.7\% vs $33.3 \%)$. However, the chi-square analysis comparing perceptions based on whether or not participants reported having witnessed ecstasy consumption was not statistically significant, $\chi^{2}(2, N=123)=3.99, p=.136$.

Perceptions regarding the credibility of witnesses who were intoxicated with both alcohol and cannabis at the time of a crime differed significantly between participants who had previous experience with polysubstance use of alcohol and cannabis and those that had not, $F E T=7.05, p$ $=0.03$, Cramer's $\mathrm{V}=0.18$. A higher proportion of participants who reported having personally experienced polysubstance intoxication with alcohol and cannabis indicated that intoxicated witnesses were "less credible" than those reporting that they had not $(82.5 \%$ and $54.5 \%$, respectively). At the same time, a lower proportion reported that they "don't know" (11.7\% and $45.5 \%$, respectively). For all other substances excluding alcohol, neither personal nor witnessed consumption was significantly related to beliefs about witness credibility when intoxicated by that substance after correcting for the family-wise error rate (all $p s>.018$ ).

Perceptions of alcohol-intoxicated witnesses did not differ significantly between participants who reported having received alcohol accreditation training and those who did not, $\chi^{2}$ $(2, N=463)=4.09, p=.132$. Interestingly, perceptions regarding the credibility of victims who were intoxicated at the time of a crime were found to differ significantly between participants who did and who did not report having received alcohol accreditation training, $\chi^{2}(2, N=455]=6.10$, 
$p=.049$, Cramer's $\mathrm{V}=.12$. In particular, a higher proportion of participants who received the training indicated that victims were "just as credible" (33.6\%) compared to those without training $(23.4 \%)$.

\section{Discussion}

This study investigated prospective jurors' perceptions of how alcohol and other drug intoxication during a crime affects eyewitness memory accuracy and credibility. In addition, we explored whether participants' familiarity with a given substance was associated with these perceptions.

\section{Perceptions regarding the negative memory effects of intoxication}

For alcohol, hallucinogens, and polysubstance use of alcohol and cannabis, participants most frequently reported believing that intoxication has a "large negative effect" on memory. In contrast, participants most frequently indicated that they "don't know" the extent to which intoxication with cannabis or cocaine negatively affects memory. This suggests that people are more likely to believe that alcohol, either alone or in combination with cannabis, has a more detrimental effect on memory than cannabis alone. For each other substance, including amphetamines, ecstasy, and sedatives, responses were relatively evenly distributed across different response options.

These results are interesting in light of the current evidence regarding the memory effects

of different substances. Specifically, for cannabis and alcohol it is well established that these substances can decrease the amount of information encoded about events experienced whilst intoxicated (e.g., Broyd et al., 2016; Jores et al., 2019). In the case of cannabis, emerging evidence indicates an increase in suggestibility during acute intoxication (medium-large effects, see Kloft, Monds, et al., 2020). There is also some evidence to suggest that relatively high doses of alcohol 
may increase susceptibility to false memories when suggestive questioning techniques are used and when witnesses are questioned after a relatively long delay (Evans et al., 2019; van Oorsouw et al., 2015). Participants' perceptions of alcohol's effects on memory are therefore consistent with false memory research showing that, in some circumstances, alcohol intoxication can result in more incorrect responses. However, meta-analyses of the eyewitness literature suggest that alcohol affects the completeness but not overall accuracy of information remembered on free and cued recall tests. This highlights the importance of advising jurors as to whether, and in what ways, intoxication with different substances is likely to have affected the testimony of witnesses and victims.

The accuracy of participants' perceptions regarding the memory effects of other substances, including ecstasy/MDMA and hallucinogens, was similarly mixed. Ecstasy/MDMA and sedatives have been found to induce amnesia for experienced events. This has included, for example, impaired verbal memory (e.g., Curran, 1991; Huron et al., 2001; Kuypers \& Ramaekers, 2005) and differential effects on false memory in word list tasks, which vary with the memory stage that is most affected (Huron et al., 2001; Kloft, Otgaar, Blokland, Toennes, et al., 2020; Mintzer \& Griffiths, 2000, 2001). Our results indicate that such effects do not appear to be wellknown in the surveyed population. There is some evidence that psychostimulants such as cocaine and amphetamines may not affect or even potentially enhance memory (Ballard et al., 2012, 2014; Spronk et al., 2013). However, there is also evidence to suggest that intoxication with these substances can increase false memory in word list tasks (Ballard et al., 2012, 2014; Kloft, Monds, et al., 2020). Results from the present investigation, which suggest potential jurors are not aware of the memory effects of such substances, reflect the preliminary and mixed nature of these research findings. As for hallucinogens, participants' perceptions that these drugs negatively 
affect memory are broadly in line with current literature, despite limitations to available research (reviewed in Kloft, Monds, et al., 2020). It should be noted, however, that these studies have generally not involved eyewitness accounts (i.e., memory for details observed during a crime) but have instead relied on basic memory tasks such as word-list recall.

Overall, the present findings highlight discrepancies between participants' perceptions regarding the effect of various substances and the degree to which these align with research findings. Participants' limited and inconsistent knowledge regarding the effects of intoxication with alcohol and other drugs on memory highlights the need for expert testimony or judicial instructions so that the effects may be appropriately considered by triers of fact.

\section{Associations with personal and witnessed consumption}

Personal and witnessed consumption of cannabis or ecstasy was associated with differences in the perception of intoxication-related memory impairment. Specifically, people who had previously consumed or witnessed consumption of either substance were more likely to state that the substance had "little negative effect" on memory. In contrast, participants that reported never having consumed or witnessed consumption of either substance were more likely to report that they "don't know" the extent to which intoxication has a negative effect on memory. One interpretation of these results is that participants perceived or observed few memory issues during their own experience with each substance and their responses were therefore in line with actual observations. Another interpretation is that substance-related effects may affect a person's metamemory (i.e., awareness of memory) by impairing recollection of memory failures (see Bedi \& Redman, 2008). This is in line with recent research indicating that cannabis acutely impairs metacognitive awareness at higher levels of confidence (Pezdek et al., 2020). However, the findings of alcohol research suggest that people who have consumed alcohol do not appear to have 
reduced meta-memory and in fact reduce confidence in their memory of events to reflect anticipated deficits (Flowe et al., 2017; Flowe et al., 2019). Relatedly, findings may reflect a selfserving bias. For example, although it appears that cannabis and ecstasy users sometimes selfreport memory impairments (Curran et al., 2002; Rodgers et al., 2001), people who use cannabis have previously not reported intoxication-related impairment to their driving (Pezdek et al., 2020; Watson et al., 2019). Further research is required to discern the underlying reasons for these findings.

With regard to perceptions of the credibility of intoxicated witnesses and victims, participants generally rated intoxicated witnesses and victims as "less credible". In terms of personal consumption, people who had previously consumed cannabis or ecstasy more frequently reported that intoxicated witnesses and victims would be "just as credible". In contrast, nonconsumers more frequently reported that they "don't know" whether intoxicated witnesses and victims would be more or less credible. For cannabis, this result was the same for people who reported previously witnessing consumption. However, perceptions regarding the credibility of witnesses and victims that were intoxicated with ecstasy did not differ on the basis of witnessed consumption. For polysubstance use of alcohol and cannabis, a higher proportion of people who had witnessed consumption of both substances indicated that intoxicated witnesses were less credible.

In the mock-juror study of Evans and Schreiber Compo (2010), personal alcohol consumption was not found to affect perceptions regarding the credibility of intoxicated witnesses/victims. The present study therefore highlights the importance of not assuming that findings in relation to alcohol are applicable to other substances and substance combinations. For the most part, perceptions regarding the effect of intoxication on credibility were similar with 
regard to both witnesses and victims. This result is in line with the study of Evans and Schreiber Compo (2010), described above, in which mock jurors did not differentiate between alcoholintoxicated victims and bystanders when providing verdicts for the mock case. While results of the study by Evans and Schreiber Compo (2010) also suggested that perspectives did not differ as a function of crime type (i.e., whether sexual or aggravated battery), future research may explore potential differences relating to intoxication with other substances.

\section{Associations with training in Responsible Service of Alcohol}

Perceptions regarding the memory accuracy and credibility of intoxicated witnesses and victims were generally not found to differ between those that reported having received training to serve alcohol for work and those that did not. One exception was that participants who reported having received training to serve alcohol were more likely to rate alcohol-intoxicated victims as "just as credible" as victims that were sober. Interestingly this perspective may be consistent with the outcomes of a recent review, which found that alcohol-intoxication is associated with a reduction in the quantity but not accuracy of information recalled (Jores et al., 2019). Although responsible service training is focused on the detection of intoxication and not the memory or credibility effects of intoxication, experience in the service of alcohol may have contributed to a more accurate perception of such effects in these participants. However, this effect was limited to perceptions regarding the credibility of victims and not other witnesses. Future research is needed to clarify the reasons for this.

\section{Limitations}

This study is not without limitations. To limit the length of the survey, only questions relating to alcohol and cannabis were made compulsory for all participants. Questions regarding each other substance and substance combination were only presented to participants that identified 
familiarity with their effects. This led to very low sample sizes for some substances, and especially for polysubstance use. Further work is necessary to explore perceptions of these substances, regardless of familiarity, as jurors will commonly have little prior knowledge of the effects of many substances with which witnesses or victims may have been intoxicated. The generalisability of the results also requires further consideration, given that the sample was largely Australian university students. Replicating the survey with a sample that is more representative of the general population will be important in future research. Jury eligibility within Australia was also not able to be confirmed, given anonymity of the data collection and the likely involvement of international students in the sample may limit generalisation in this regard. Nevertheless, these results offer an important first step in exploring potential juror perceptions of AOD use and how they might impact decisions about witness memory and credibility.

It is also worth acknowledging the likely overlap between perceptions regarding memory and those of credibility, as witness credibility is likely to incorporate an assessment of memory reliability. Despite this, perceptions regarding credibility are also likely to have considered concepts such as honesty and trustworthiness (Bruer \& Pozzulo, 2014). Results may therefore reflect stigma around substance use, particularly with regard to illegal substances. However, it should be noted that the credibility items were presented immediately following the question regarding how intoxication affects memory. As a result, it is possible that participants focused on reliability of memory more so than believability when judging how AOD intoxication impacts credibility. Further jury research is needed to explore the different components of AOD-related credibility within legal trials. 


\section{Conclusions}

Overall, these findings have important implications for the legal system. Different substances of intoxication are potentially viewed differently by lay people in terms of their memory-impairing effects and the impact on credibility. In some cases, these perceptions are not in line with current evidence regarding the effect of substances on memory. These results therefore highlight the importance of incorporating expert witness testimony regarding AOD effects into court cases involving intoxication with specific substances, to ensure jurors are able to make informed decisions regarding their impact. A further implication of the present study is that potential jurors may interpret a case involving an intoxicated witness or victim differently, depending on their own familiarity with the substance or combination of substances involved. This may be essential to informing legal decisions during voir dire procedures. Future research is needed to explore how expert testimony about the memory effects of different substances will impact perceptions. This is especially the case if the findings from the research literature are at odds with perceptions held by people who have personal experiences with the drug, whether by their own use or observing others. By improving the accuracy with which this information may be incorporated into judicial processes, an improved understanding of perceptions regarding the memory and credibility effects of AOD intoxication will serve to deliver better and fairer outcomes for all. 


\section{References}

AIHW. (2016). 2016 National drug strategy household survey report. Australian Institute of Health and Welfare.

Altman, C., Compo, N. S., Hagsand, A. V., \& Evans, J. R. (2019). State of intoxication: A review of the effects of alcohol on witnesses' memory. In Evidence-based investigative interviewing (pp. 74-92). Routledge.

Altman, C., Schreiber Compo, N., McQuiston, D., Hagsand, A. V., \& Cervera, J. (2018). Witnesses' memory for events and faces under elevated levels of intoxication. Memory, 26(7), 946-959. https://doi.org/10.1080/09658211.2018.1445758

Ballard, M. E., Gallo, D. A., \& de Wit, H. (2012). Psychoactive drugs and false memory: comparison of dextroamphetamine and delta-9-tetrahydrocannabinol on false recognition. Psychopharmacology, 219(1), 15-24. https://doi.org/10.1007/s00213-011-2374-5

Ballard, M. E., Gallo, D. A., \& de Wit, H. (2014). Amphetamine increases errors during episodic memory retrieval. Journal of Clinical Psychopharmacology, 34(1), 85-92. https://doi.org/10.1097/jcp.0000000000000039

Bedi, G., \& Redman, J. (2008). Metamemory in recreational ecstasy polydrug users: what do selfreports of memory failures mean? Journal of Psychopharmacology, 22(8), 872-881. https://doi.org/10.1177/0269881107083811

Benton, T. R., Ross, D. F., Bradshaw, E., Thomas, W. N., \& Bradshaw, G. S. (2006). Eyewitness memory is still not common sense: comparing jurors, judges and law enforcement to eyewitness experts. Applied Cognitive Psychology, 20(1), 115-129. https://doi.org/10.1002/acp.1171 
Broyd, S. J., van Hell, H. H., Beale, C., Yücel, M., \& Solowij, N. (2016). Acute and Chronic Effects of Cannabinoids on Human Cognition-A Systematic Review. Biological Psychiatry, 79(7), 557-567. https://doi.org/10.1016/j.biopsych.2015.12.002

Bruer, K., \& Pozzulo, J. D. (2014). Influence of eyewitness age and recall error on mock juror decision-making. Legal and Criminological Psychology, 19(2), 332-348. https://doi.org/10.1111/lcrp.12001

Bush, K., Kivlahan, D. R., McDonell, M. B., Fihn, S. D., \& Bradley, K. A. (1998). The AUDIT alcohol consumption questions (AUDIT-C): an effective brief screening test for problem drinking. Archives of internal medicine, 158(16), 1789-1795. https://doi.org/10.1001/archinte.158.16.1789

Colloff, M. F., \& Flowe, H. D. (2016). The effects of acute alcohol intoxication on the cognitive mechanisms underlying false facial recognition. Psychopharmacology, 233(11), 21392149. https://doi.org/10.1007/s00213-016-4263-4

Crossland, D., Kneller, W., \& Wilcock, R. (2018). Intoxicated eyewitnesses: prevalence and procedures according to England's police officers. Psychology, Crime \& Law, 1-19. https://doi.org/10.1080/1068316x.2018.1474216

Curran, V. H. (1991). Benzodiazepines, memory and mood: a review. Psychopharmacology, 105(1), 1-8. https://doi.org/10.1007/bf02316856

Curran, V. H., Brignell, C., Fletcher, S., Middleton, P., \& Henry, J. (2002). Cognitive and subjective dose-response effects of acute oral $\Delta 9$-tetrahydrocannabinol (THC) in infrequent cannabis users. Psychopharmacology, 164(1), 61-70. https://doi.org/10.1007/s00213-002-1169-0 
Dietze, P., Jenkinson, R., Aitken, C., Stoové, M., Jolley, D., Hickman, M., \& Kerr, T. (2013). The relationship between alcohol use and injecting drug use: Impacts on health, crime and wellbeing. Drug and Alcohol Dependence, 128(1), 111-115. https://doi.org/10.1016/j.drugalcdep.2012.08.013

Evans, J. R., \& Schreiber Compo, N. (2010). Mock jurors' perceptions of identifications made by intoxicated eyewitnesses. Psychology, Crime \& Law, 16(3), 191-210. https://doi.org/10.1080/10683160802612890

Evans, J. R., Schreiber Compo, N., Carol, R. N., Nichols-Lopez, K., Holness, H., \& Furton, K. G. (2019). The impact of alcohol intoxication on witness suggestibility immediately and after a delay. Applied Cognitive Psychology, 33(3), 358-369. https://doi.org/10.1002/acp.3502

Evans, J. R., Schreiber Compo, N., \& Russano, M. B. (2009). Intoxicated witnesses and suspects: Procedures and prevalence according to law enforcement. Psychology, Public Policy, and Law, 15(3), 194. https://doi.org/10.1037/a0016837

Flowe, H. D., Colloff, M. F., Karoğlu, N., Zelek, K., Ryder, H., Humphries, J. E., \& Takarangi, M. K. T. (2017). The Effects of Alcohol Intoxication on Accuracy and the ConfidenceAccuracy Relationship in Photographic Simultaneous Line-ups. Applied Cognitive Psychology, 31(4), 379-391. https://doi.org/10.1002/acp.3332

Flowe, H. D., Humphries, J. E., Takarangi, M. K., Zelek, K., Karoğlu, N., Gabbert, F., \& Hope, L. (2019). An experimental examination of the effects of alcohol consumption and exposure to misleading postevent information on remembering a hypothetical rape scenario. Applied Cognitive Psychology, 33(3), 393-413. https://doi.org/10.1002/acp.3531 
Flowe, H. D., Mehta, A., \& Ebbesen, E. B. (2011). The role of eyewitness identification evidence in felony case dispositions. Psychology, Public Policy, and Law, 17(1), 140-159. https://doi.org/10.1037/a0021311

Flowe, H. D., Takarangi, M. K. T., Humphries, J. E., \& Wright, D. S. (2016). Alcohol and remembering a hypothetical sexual assault: Can people who were under the influence of alcohol during the event provide accurate testimony? Memory, 24(8), 1042-1061. https://doi.org/10.1080/09658211.2015.1064536

Houston, K. A., Hope, L., Memon, A., \& Don Read, J. (2013). Expert Testimony on Eyewitness Evidence: In Search of Common Sense. Behavioral sciences \& the law, 31(5), 637-651. https://doi.org/10.1002/bsl.2080

Huron, C., Servais, C., \& Danion, J.-M. (2001). Lorazepam and diazepam impair true, but not false, recognition in healthy volunteers. Psychopharmacology, 155(2), 204-209. https://doi.org/10.1007/s002130100683

Innocence Project. (2020). How Eyewitness Misidentification Can Send Innocent People to Prison. Retrieved 4th December 2020 from https://innocenceproject.org/how-eyewitnessmisidentification-can-send-innocent-people-to-prison/

Jores, T., Colloff, M. F., Kloft, L., Smailes, H., \& Flowe, H. D. (2019). A meta-analysis of the effects of acute alcohol intoxication on witness recall. Applied Cognitive Psychology. https://doi.org/10.1002/acp.3533

Kassin, S. M., \& Gudjonsson, G. H. (2004). The Psychology of Confessions: A Review of the Literature and Issues. Psychological Science in the Public Interest, 5(2), 33-67. https://doi.org/10.1111/j.1529-1006.2004.00016.x 
Kloft, L., Monds, L., Blokland, A., Ramaekers, J., \& Otgaar, H. (2020). Hazy memories in the courtroom: a review of alcohol and other drug effects on false memory and suggestibility. [Manuscript submitted for publication]. Faculty of Psychology and Neuroscience, Maastricht University.

Kloft, L., Otgaar, H., Blokland, A., Monds, L. A., Toennes, S. W., Loftus, E. F., \& Ramaekers, J. G. (2020). Cannabis increases susceptibility to false memory. Proceedings of the National Academy of Sciences, 117(9), 4585-4589. https://doi.org/10.1073/pnas.1920162117

Kloft, L., Otgaar, H., Blokland, A., Toennes, S. W., \& Ramaekers, J. G. (2020). Remembering Molly: immediate and delayed false memory formation after acute MDMA exposure. [Manuscript submitted for publication]. Faculty of Psychology and Neuroscience, Maastricht University.

Kuypers, K. P. C., \& Ramaekers, J. G. (2005). Transient memory impairment after acute dose of 75mg 3.4-Methylene-dioxymethamphetamine. Journal of Psychopharmacology, 19(6), 633-639. https://doi.org/10.1177/0269881105056670

Lynch, K. R., Wasarhaley, N. E., Golding, J. M., \& Simcic, T. (2013). Who Bought the Drinks? Juror Perceptions of Intoxication in a Rape Trial. Journal of Interpersonal Violence, 28(16), 3205-3222. https://doi.org/10.1177/0886260513496900

Mindthoff, A., Evans, J. R., Perez, G., Woestehoff, S. A., Olaguez, A. P., Klemfuss, J. Z., Vallano, J. P., Woody, W. D., Normile, C. J., Scherr, K. C., Carlucci, M. E., Carol, R. N., Hayes, T., Meissner, C. A., Michael, S. W., Russano, M. B., \& Stocks, E. L. (2019). Juror Perceptions of Intoxicated Suspects' Interrogation-Related Behaviors. Criminal Justice and Behavior, 47(2), 222-246. https://doi.org/10.1177/0093854819888962 
Mintzer, M. Z., \& Griffiths, R. R. (2000). Acute effects of triazolam on false recognition. Memory \& Cognition, 28(8), 1357-1365. https://doi.org/10.3758/BF03211836

Mintzer, M. Z., \& Griffiths, R. R. (2001). False Recognition in Triazolam-Induced Amnesia. Journal of memory and language, 44(3), 475-492. https://doi.org/10.1006/jmla.2000.2746

Monds, L. A., Kloft, L., Sauer, J. D., Honan, C. A., \& Palmer, M. A. (2019). No evidence that alcohol intoxication impairs judgments of learning in face recognition. Applied Cognitive Psychology. https://doi.org/10.1002/acp.3534

Monds, L. A., van Golde, C., Takarangi, M., Paterson, H., \& Flowe, H. (2017). Assessing the reliability of intoxicated witnesses. Australian Police Journal, 121-128. https://doi.org/Retrieved from https://apjl.com.au/issues/year/2017

Palmer, F. T., Flowe, H. D., Takarangi, M. K., \& Humphries, J. E. (2013). Intoxicated witnesses and suspects: an archival analysis of their involvement in criminal case processing. Law and human behavior, 37(1), 54. https://doi.org/10.1037/lhb0000010

Pezdek, K., Abed, E., \& Reisberg, D. (2020). Marijuana Impairs the Accuracy of Eyewitness Memory and the Confidence-Accuracy Relationship Too. Journal of Applied Research in Memory and Cognition, 9(1), 60-67. https://doi.org/10.1016/j.jarmac.2019.11.005

Quilter, J., \& McNamara, L. (2018). The Meaning of “Intoxication” in Australian Criminal Cases: Origins and Operation. New Criminal Law Review, 21(1), 170-207. https://doi.org/10.1525/nclr.2018.21.1.170

Rodgers, J., Buchanan, T., Scholey, A. B., Heffernan, T. M., Ling, J., \& Parrott, A. (2001). Differential effects of Ecstasy and cannabis on self-reports of memory ability: a web-based study. Human Psychopharmacology: Clinical and Experimental, 16(8), 619-625. https://doi.org/10.1002/hup.345 
Schreiber Compo, N., Evans, J. R., Carol, R. N., Villalba, D., Ham, L. S., Garcia, T., \& Rose, S. (2012). Intoxicated eyewitnesses: Better than their reputation? Law and human behavior, 36(2), 77. https://doi.org/10.1037/h0093951

Schuller, R. A., \& Wall, A.-M. (1998). The effects of defendant and complainant intoxication on mock jurors' judgements of sexual assault. Psychology of Women Quarterly, 22(4), 555573. https://doi.org/10.1111/j.1471-6402.1998.tb00177.x

Slovenko, R. (2004). Testimony on Credibility: A Case Analysis. The Journal of Psychiatry \& Law, 32(2), 243-268. https://doi.org/10.1177/009318530403200212

Spronk, D. B., van Wel, J. H. P., Ramaekers, J. G., \& Verkes, R. J. (2013). Characterizing the cognitive effects of cocaine: A comprehensive review. Neuroscience \& Biobehavioral Reviews, 37(8), 1838-1859. https://doi.org/10.1016/j.neubiorev.2013.07.003

van Oorsouw, K., Broers, N. J., \& Sauerland, M. (2019). Alcohol intoxication impairs eyewitness memory and increases suggestibility: Two field studies. Applied Cognitive Psychology, 33(3), 439-455. https://doi.org/10.1002/acp.3561

van Oorsouw, K., \& Merckelbach, H. (2012). The Effects of Alcohol on Crime-related Memories: A Field Study. Applied Cognitive Psychology, 26(1), 82-90. https://doi.org/10.1002/acp.1799

van Oorsouw, K., Merckelbach, H., \& Smeets, T. (2015). Alcohol Intoxication Impairs Memory and Increases Suggestibility for a Mock Crime: A Field Study. Applied Cognitive Psychology, 29(4), 493-501. https://doi.org/10.1002/acp.3129

Vredeveldt, A., Charman, S. D., den Blanken, A., \& Hooydonk, M. (2018). Effects of cannabis on eyewitness memory: A field study. Applied Cognitive Psychology, 1-9. https://doi.org/10.1002/acp.3414 
Watson, T. M., Mann, R. E., Wickens, C. M., \& Brands, B. (2019). “Just a Habit”: Driving Under the Influence of Cannabis as Ordinary, Convenient, and Controllable Experiences According to Drivers in a Remedial Program. Journal of Drug Issues, 49(3), 531-544. https://doi.org/10.1177/0022042619842375

Winstock, A. R. (2019). GDS2019 KEY FINDINGS REPORT | EXECUTIVE SUMMARY. https://www.globaldrugsurvey.com/wpcontent/themes/globaldrugsurvey/results/GDS2019-Exec-Summary.pdf

Yuille, J. C., Tollestrup, P. A., Marxsen, D., Porter, S., \& Herve, H. F. (1998). An exploration on the effects of marijuana on eyewitness memory. International Journal of Law and Psychiatry, 21(1), 117-128. https://doi.org/10.1016/s0160-2527(97)00027-7 


\section{Acknowledgements}

The authors thank Dr Jacqueline Evans for kindly providing her survey to be adapted for this study.

We also thank Matthew Singleton for his help in editing the manuscript.

\section{Data Availability Statement}

Due to the nature of this research, participants of this study did not agree for their data to be shared publicly, so supporting data is not available.

\section{Declaration of Conflicts of Interest}

The authors have no competing interests to declare. 


\section{Appendix - Survey Questions}

\section{Instructions}

This questionnaire will ask you about

1. your experiences with alcohol and other drugs;

2. your opinions on the cues and signs of intoxication for different substances and;

3. your perceptions of victim/eyewitness credibility and memory for someone intoxicated by particular substances during an event

Your answers to this questionnaire are confidential.

Please click >> when you are ready to continue.

\section{Demographic Questions}

1. Please enter your age

2. Please select your gender (Male, Female, Other)

3. Please enter your country of residence

4. Which of the following best describes your current employment status? (Full-time, part-time, casual, unemployed, student, carer/home duties, retired)

\section{Substance Familiarity}

Which of the following drugs/substances do you have experience with (e.g. have personally consumed, have witnessed someone else consuming, or have general knowledge about its effects)? Please select all that apply.

- Alcohol

- Amphetamines (e.g. Crystal Meth, Speed) 
- Cannabis

- Cocaine

- Ecstasy

- Hallucinogens (e.g. Ketamine, Psilocybin Mushrooms, DMT)

- Heroin

- Sedatives (e.g. Benzodiazepines, Sleeping Medication, Antihistamines)

- GHB (e.g. Liquid Ecstasy, Fantasy)

- None

\section{Alcohol Questions}

The following questions will ask you about your experiences with alcohol intoxication. Intoxication refers to when an individual is affected temporarily by a substance and subsequently has diminished mental and physical control.

1. Do you currently, or have you ever worked in a role where you were required to serve alcohol? ("Yes", "No")

2. Have you completed any compulsory training/accreditation for serving alcohol? ("Yes", "No")

a) If you selected "Yes", please provide the name of your accreditation (e.g. Responsible Service of Alcohol) and the country it was completed in.

3. How often do you have a drink containing alcohol? ("Never", "Less than monthly", "Monthly", "Weekly", "Daily or almost daily", "Prefer not to answer”)

4. How many standard drinks containing alcohol do you have on a typical day? ("1 or 2", "3 or 4", "5 or 6", "7 to 9", “10 or more”, "Prefer not to answer”) 
5. How often do you have six or more drinks on one occasion (i.e. in the one sitting)? ("Never", "Less than monthly”, "Monthly", "Weekly”, "Daily or almost daily”, "Prefer not to answer”)

6. How often do you witness other people drinking alcohol? ("Never", "Less than monthly", "Monthly", "Weekly", "Daily or almost daily", "Prefer not to answer")

7. How often do you witness other people intoxicated by alcohol? ("Never", "Less than monthly", "Monthly", "Weekly", "Daily or almost daily", "Prefer not to answer")

8. Have you ever been a witness to an alcohol-related crime (e.g. committed by, or against, someone under the influence of alcohol; not merely the illegal use of this substance)? ("Yes", "no", "Prefer not to answer")

a) If "yes", describe the nature of this crime (e.g. physical assault, theft, etc.; if more than one instance, please state the most common crime)

9. How difficult do you find it to tell when someone is intoxicated by alcohol? ("Extremely difficult", "Somewhat difficult", "Neither easy nor difficult", "Somewhat easy", "Extremely easy", "Prefer not to answer")

10. What visual cues would you look for to determine whether someone is intoxicated by alcohol? Please list up to three visual cues.

a) For each visual cue you listed, how reliable would you consider this cue to be (in terms of consistently identifying intoxication rather than something else)? ("Not at all reliable", "Slightly reliable", "Moderately reliable", "Very reliable", "Extremely reliable”, "I don’t know", "Prefer not to answer")

11. What verbal cues would you look for to determine whether someone is intoxicated by alcohol? Please list up to three verbal cues. 
a) For each verbal cue you listed, how reliable would you consider this cue to be (in terms of consistently identifying intoxication rather than something else)? ("Not at all reliable", "Slightly reliable", "Moderately reliable", "Very reliable", "Extremely reliable”, "I don't know", "Prefer not to answer")

12. Are there any other signs you would look for (not previously mentioned) to determine whether someone is intoxicated by alcohol? ("Yes", "No", "Prefer not to answer")

a) If "yes", please list any other signs you would look for to determine whether someone is intoxicated by alcohol.

13. To what degree do you believe alcohol intoxication negatively affects a person's memory of events? ("Not at all”, "Slightly", "Moderately", "Very much", "Extremely", "I don’t know”, "Prefer not to answer")

a) Please provide a reason for your rating.

14. Do you believe a witness who is intoxicated by alcohol while witnessing a crime is more credible, less credible, or just as credible as a sober witness? (“More”, "Less", “Just as", “I don’t know", "Prefer not to answer")

a) Please provide a reason for your rating.

15. Do you believe a victim who is intoxicated by alcohol while witnessing a crime is more credible, less credible, or just as credible as a sober victim? ("More”, “Less", "Just as”, "I don’t know", "Prefer not to answer")

a) Please provide a reason for your rating.

16. At which point in time do you think witnesses intoxicated by alcohol would be the most accurate? ("Soon after the crime, while still intoxicated by alcohol”; "As soon as they are sober 
from alcohol"; "After a delay when intoxicated by alcohol again"; "After a delay when sober from alcohol"; "I don't know"; "Prefer not to answer")

a) Please provide a reason for your rating

17. At which point in time do you think victims intoxicated by alcohol would be the most accurate? ("Soon after the crime, while still intoxicated by alcohol"; "As soon as they are sober from alcohol"; "After a delay when intoxicated by alcohol again"; "After a delay when sober from alcohol"; "I don't know"; "Prefer not to answer")

a) Please provide a reason for your rating

\section{All Other Substance Questions}

18. How often do you consume [substance]? ("Never", "Less than monthly", "Monthly", “Weekly”, "Daily or almost daily", "Prefer not to answer")

19. How often do you witness other people consuming, or under the influence of [substance]? ("Never", "Less than monthly", "Monthly", "Weekly", "Daily or almost daily", "Prefer not to answer")

20. Have you ever been a witness to a [substance]-related crime (e.g. committed by, or against, someone under the influence of [substance]; not merely the illegal use of this substance)? ("Yes", "No", "Prefer not to answer")

a) If "yes", describe the nature of this crime (e.g. physical assault, theft, etc.; if more than one instance, please state the most common crime)

21. How difficult do you find it to tell when someone is intoxicated by [substance]? ("Extremely difficult", "Somewhat difficult", "Neither easy nor difficult", "Somewhat easy", "Extremely easy", "Prefer not to answer") 
22. What visual cues would you look for to determine whether someone is intoxicated by [substance]? Please list up to three visual cues.

a) For each visual cue you listed, how reliable would you consider this cue to be (in terms of consistently identifying intoxication rather than something else)? ("Not at all reliable", "Slightly reliable", "Moderately reliable", "Very reliable", "Extremely reliable", "I don’t know", "Prefer not to answer")

23. What verbal cues would you look for to determine whether someone is intoxicated by [substance]? Please list up to three verbal cues.

a) For each verbal cue you listed, how reliable would you consider this cue to be (in terms of consistently identifying intoxication rather than something else)? ("Not at all reliable", "Slightly reliable", "Moderately reliable", "Very reliable", "Extremely reliable", "I don’t know", "Prefer not to answer")

24. Are there any other signs you would look for (not previously mentioned) to determine whether someone is intoxicated by [substance]? ("Yes", "No", "Prefer not to answer")

a) If "yes", please list any other signs you would look for to determine whether someone is intoxicated by [substance].

25. To what degree do you believe [substance] intoxication negatively affects a person's memory of events? ("Not at all”, "Slightly", "Moderately", "Very much", "Extremely", “I don’t know", "Prefer not to answer")

a) Please provide a reason for your rating.

26. Do you believe a witness who is intoxicated by [substance] while witnessing a crime is more credible, less credible, or just as credible as a sober witness? ("More", "Less", "Just as", "I don’t know", "Prefer not to answer") 
a) Please provide a reason for your rating.

27. Do you believe a victim who is intoxicated by [substance] while witnessing a crime is more credible, less credible, or just as credible as a sober victim? ("More”, “Less", “Just as”, "I don’t know", "Prefer not to answer")

a) Please provide a reason for your rating.

28. At which point in time do you think witnesses intoxicated by [substance] would be the most accurate? ("Soon after the crime, while still intoxicated by [substance]"; "As soon as they are sober from [substance]"; "After a delay when intoxicated by [substance] again"; "After a delay when sober from [substance]"; "I don't know"; "Prefer not to answer")

a) Please provide a reason for your rating

29. At which point in time do you think victims intoxicated by [substance] would be the most accurate? ("Soon after the crime, while still intoxicated by [substance]"; "As soon as they are sober from [substance]"; "After a delay when intoxicated by [substance] again"; "After a delay when sober from [substance]"; "I don't know"; "Prefer not to answer")

a) Please provide a reason for your rating 
Table 1

Percentage of Survey Respondents who Reported Familiarity with Each Substance

\begin{tabular}{|c|c|c|c|c|}
\hline Substance & $\begin{array}{c}\text { Respondents } \\
\text { familiar with } \\
\text { substance }(\%)\end{array}$ & $n$ & Consumed (\%) & Witnessed (\%) \\
\hline Alcohol & 93.6 & 470 & 86.1 & 97.9 \\
\hline Cannabis & 51.1 & 470 & 17.5 & 52.5 \\
\hline Sedatives & 29.6 & 139 & 51.5 & 63.4 \\
\hline Ecstasy & 27.2 & 128 & 28.9 & 66.4 \\
\hline Cocaine & 24.5 & 115 & 21.9 & 56.6 \\
\hline Hallucinogens & 18.7 & 88 & 27.1 & 48.2 \\
\hline Amphetamines & 15.5 & 73 & 23.6 & 47.9 \\
\hline Heroin & 8.9 & 42 & $0^{\mathrm{a}}$ & 15.4 \\
\hline GHB & 4.9 & 23 & 17.4 & 39.1 \\
\hline No familiarity & 5.7 & & & \\
\hline $\begin{array}{l}\text { Polysubstance } \\
\text { intoxication }\end{array}$ & 33.7 & 469 & & \\
\hline $\begin{array}{l}\text { Alcohol and } \\
\text { Cannabis }\end{array}$ & 30.9 & 145 & 27.6 & 88.3 \\
\hline $\begin{array}{l}\text { Alcohol and } \\
\text { Ecstasy }\end{array}$ & 10.4 & 49 & 34.0 & 80.0 \\
\hline $\begin{array}{l}\text { Alcohol and } \\
\text { Cocaine }\end{array}$ & 8.5 & 40 & 41.5 & 75.6 \\
\hline $\begin{array}{l}\text { Alcohol and } \\
\text { Hallucinogens }\end{array}$ & 4.0 & 19 & 20.0 & 65.0 \\
\hline $\begin{array}{l}\text { Alcohol and } \\
\text { Amphetamines }\end{array}$ & 3.0 & 14 & 28.6 & 57.1 \\
\hline $\begin{array}{l}\text { Cannabis and } \\
\text { Amphetamines }\end{array}$ & 1.5 & 7 & 28.6 & 71.4 \\
\hline $\begin{array}{l}\text { Alcohol and } \\
\text { Heroin }\end{array}$ & 1.1 & 5 & 0 & 60.0 \\
\hline Other & 1.1 & 5 & 42.9 & 42.9 \\
\hline
\end{tabular}

${ }^{\mathrm{a}} 97.6 \%$ never consumed, $2.4 \%$ prefer not to answer 
Table 2

Responses (\%) as to Whether the Substance Negatively Impacts Upon Memory

\begin{tabular}{lccccccc}
\multicolumn{1}{c}{ Substance } & $n$ & $\begin{array}{c}\text { Little } \\
\text { negative } \\
\text { effect }\end{array}$ & $\begin{array}{c}\text { Moderate } \\
\text { negative } \\
\text { effect }\end{array}$ & $\begin{array}{c}\text { Large } \\
\text { negative } \\
\text { effect }\end{array}$ & $\begin{array}{c}\text { Don't } \\
\text { know }\end{array}$ & $\chi^{2}$ & $p$ \\
\hline Alcohol & 465 & 5.6 & 30.3 & 62.8 & 1.3 & 445.60 & $<.001$ \\
Cannabis & 456 & 25.2 & 21.3 & 21.1 & 32.5 & 15.53 & .001 \\
Amphetamines & 70 & 24.3 & 17.1 & 34.3 & 24.3 & 4.10 & .251 \\
Cocaine & 109 & 28.4 & 11.9 & 20.2 & 39.4 & 18.08 & $<.001$ \\
Ecstasy & 125 & 25.6 & 16.8 & 26.4 & 31.2 & 5.49 & .139 \\
Hallucinogens & 81 & 6.3 & 8.6 & 66.7 & 18.5 & 77.77 & $<.001$ \\
Sedatives & 131 & 32.8 & 22.9 & 19.8 & 24.4 & 4.85 & .183 \\
Alcohol and & 135 & 5.9 & 22.2 & 57.0 & 14.8 & 85.04 & $<.001$ \\
Cannabis & & & & & & & \\
\hline
\end{tabular}


Table 3

Responses (\%) as to Whether an Intoxicated Witness is Less, Just as, or More Credible than a Sober Witness

\begin{tabular}{lcccccc}
\hline \multicolumn{1}{c}{ Substance } & $n$ & $\begin{array}{c}\text { Less } \\
\text { credible }\end{array}$ & $\begin{array}{c}\text { Just as } \\
\text { credible }\end{array}$ & $\begin{array}{c}\text { Don't } \\
\text { know }\end{array}$ & $\chi^{2}$ & $p$ \\
\hline Alcohol & 463 & 87.2 & 6.5 & 6.3 & 605.84 & $<.001$ \\
Cannabis & 445 & 58.7 & 14.4 & 27.0 & 138.94 & $<.001$ \\
Amphetamines & 68 & 61.8 & 16.2 & 22.0 & 25.09 & $<.001$ \\
Cocaine & 106 & 45.3 & 18.0 & 36.8 & 12.47 & .002 \\
Ecstasy & 124 & 61.3 & 13.7 & 25.0 & 45.98 & $<.001$ \\
Hallucinogens & 79 & 82.3 & 2.6 & 15.1 & 87.06 & $<.001$ \\
Sedatives & 127 & 56.0 & 18.1 & 26.0 & 30.30 & $<.001$ \\
Alcohol and Cannabis & 136 & 79.4 & 5.9 & 14.7 & 131.53 & $<.001$ \\
\hline
\end{tabular}




\section{Table 4}

Responses (\%) as to Whether an Intoxicated Victim is Less, Just as, or More Credible than a Sober Victim

$\begin{array}{cccccc}\text { Substance } & n & \begin{array}{c}\text { Less } \\ \text { credible }\end{array} & \begin{array}{c}\text { Just as } \\ \text { credible }\end{array} & \begin{array}{c}\text { Don't } \\ \text { know }\end{array} & \chi^{2}\end{array}$

\begin{tabular}{lcccccr}
\hline Alcohol & 455 & 59.6 & 26.2 & 14.3 & 150.45 & $<.001$ \\
Cannabis & 448 & 50.0 & 21.0 & 29.0 & 60.34 & $<.001$ \\
Amphetamines & 69 & 56.5 & 18.8 & 24.6 & 17.04 & $<.001$ \\
Cocaine & 106 & 41.5 & 19.8 & 38.7 & 8.85 & .012 \\
Ecstasy & 122 & 54.1 & 19.7 & 26.2 & 24.46 & $<.001$ \\
Hallucinogens & 80 & 72.5 & 6.3 & 21.3 & 57.93 & $<.001$ \\
Sedatives & 126 & 59.6 & 26.2 & 14.3 & 4.33 & .115 \\
Alcohol and Cannabis & 136 & 71.3 & 13.2 & 15.4 & 88.43 & $<.001$ \\
\hline
\end{tabular}

